\title{
Marketing competition on a new product introduction - a structural analysis using systems thinking
}

\section{Stefano Armenia* and Alessandro Pompei}

Università degli Studi di Roma 'La Sapienza', Piazzale Aldo Moro 5, 00185 Rome, Italy

Email: armenia@dis.uniroma1.it

Email: ales.pompei@gmail.com

*Corresponding author

\section{Vittorio Pupillo}

Via Renzo da Ceri 57, 00176 Rome, Italy

Email: vittogol@hotmail.com

\section{Fabio Nonino}

Università degli Studi di Roma 'La Sapienza', Piazzale Aldo Moro 5, 00185 Rome, Italy

Email: fabio.nonino@uniroma1.it

\begin{abstract}
Launching a new product on the market is a strategic activity that needs specific investments and a specific organisation. There are multiple factors that determine the success of a new product on the market but their direct effects are not often very well observable (marketing for example). With this study, we analysed the systemic structure underlying the dynamics related to the introduction of a new product on the market. In particular, we built a qualitative model based on the systems thinking methodology of causal-loop diagrams (CLDs), starting from the main structure and assumptions of the well-known Bass model. The model provides a systemic perspective on the interdependencies among various aspects that interact in important organisational areas. The presented causal-loop diagram tries to describe the systems structure which is intrinsic to the introduction and diffusion of a new product on the market, and how ultimately the related dynamics could be managed.
\end{abstract}

Keywords: marketing competition; systems thinking; marketing strategy; word-of-mouth; new product diffusion; customer satisfaction.

Reference to this paper should be made as follows: Armenia, S., Pompei, A.., Pupillo, V. and Nonino, F. (xxxx) 'Marketing competition on a new product introduction - a structural analysis using systems thinking', Int. J. Markets and Business Systems, Vol. X, No. Y, pp.xxx-xxx.

Biographical notes: Stefano Armenia is a Research Fellow in the Analysis of Dynamical Systems at the Center for Cyber Intelligence and Information Security, 'Sapienza' University of Rome. He holds a degree in Computer Engineering, Industrial Automation and Control Systems, a PhD in Business 
Engineering and a Master in Management and Business Administration. He is member of the System Dynamics International Society (SDS) since 2002, President of SYDIC (the Italian Network of the SDS) since 2011 and member of the SDS Policy Council since 2014. Since 2014 he is also the IT and communication manager of the European Academy of Management.

Alessandro Pompei has a Master degree in Industrial and Management Engineering at 'La Sapienza' University of Rome. He is also a reviewer for the 'Kybernetes' journal and the International Journal of Systems \& Cybernetics.

Vittorio Pupillo is a Business Consultant Professional in Marketing and Sales Processes. He has a degree in Industrial and Management Engineering at the Tor Vergata University of Rome. Currently, he is cooperating with La Sapienza University of Rome, Department of Computer, Automation and Management Engineering 'Antonio Ruberti' as an advisor on business systems modelling. $\mathrm{He}$ is also a reviewer for the 'Kybernetes' journal, and the International Journal of Systems \& Cybernetics. He has an extensive working experience in the private sector. For ten years, he worked as an international business developer, in particular in Middle East and Asia Pacific Regions.

Fabio Nonino is an Associate Professor of Management Engineering at the Sapienza University of Rome. He holds a PhD in Management Engineering from the Padua University. His principal research interests concern operations and project management, innovation management and informal organisational networks. His main publications appeared in Supply Chain Management, Production Planning \& Control, International Journal of Production Research, OMEGA and International Journal of Project Management.

\section{Introduction}

The purpose of this study is to shed light on the systemic structure underlying consumer's attitudes towards a certain product/service or another, hence aiming at understanding what is the rationale for the dynamics related to the spread of a certain product inside the market, what are the obstacles to such a diffusion and which strategies can be identified to make the product 'survive' during the first period in which the product itself is first launched on the market.

Nowadays, only a small percentage of launched products become a market leader, like said by Penconek and Sjöstrand (2015) in the Nielsen's breakthrough innovation report " 3 over 4 of the new products are unable to reach a threshold of 140,000 EUR over the first 12 months from their launch on the market". This is probably due not only to a growing attention paid from customers to the personalisation of the products they buy, but also to the high competition among products in the same market niche. What we want to show is that a winning strategy is not only to use marketing tools carefully and with the right timing but also to improve the product experience gradually, introducing a product/service which is sufficiently mature to be accepted by the market.

It is also important to highlight that firm's innovation strategy should be strictly tied with its innovation ecosystem (Ries, 2005). According to Adner (2006), "Even if a firm develops its own innovation brilliantly, meets and exceeds its customers' needs, and successfully excludes its rivals, a market may not emerge. Whether - and when - it emerges is determined as much by the firm's partners as by its own performance." This 
aspect gives more complexity to the system, because it strongly influences customers' expectation and satisfaction. These last two aspects will be crucial in our model.

When a company first offers a new category of products/services on the market, it is defined 'first mover', and sooner or later it is being followed by other companies that understand and decide that market can be profitable, and are for this defined as followers (Shilling, 2009). These latter ones are the antagonists of the first mover (if it has implemented a correct strategy) or can become themselves market leaders if they are better prepared strategically, if they have more money to support the product in its introduction in the market or if they make a better use of marketing tools or in other words, if they are capable of being more effective on the market (Ries and Trout, 1994). In all such cases, there is no predetermined (or known in advance) obvious outcome: sometimes the first mover wins the competition, sometimes not (followers win or in other cases, equilibrium is reached). There are many examples of this situation (apart for monopoly situations, of course) and there are also a good number of case studies. For example, in the microprocessors market, there was a first mover (Intel) that was later followed by other companies (i.e., AMD, Cyrix, etc.) but the leadership is still on the Intel side (Shilling, 2009). On the contrary, as it concerns the operating systems market, it is today common knowledge how the situation developed over the last 40 years: Digital Research got it started but Microsoft later became the market leader (Shilling, 2009).

This paper aims at demonstrating that the success of a certain product is not depending only on the acceptance it gets from consumers; rather (and mostly) it depends on how competitors will move strategically. The concept of 'market defence' is a multidimensional phenomenon, although most of the research so far has examined a limit number of its dimensions (Kuester et al., 1999). The real leverage in most management situations lies in understanding dynamic complexity, and not in detailing such a complexity (Senge, 1990). Developing a profitable mix of price, product (or service) quality, design, and availability that contribute to determine a strong market position is a dynamic problem (Senge, 1990). Our opinion, based on marketing research and practice, as well as on the knowledge of the concepts that associate dynamic behaviour to the underlying structure of a system, is that the systems thinking approach can provide an integrative view of complex and dynamic problems like market strategy.

The initial qualitative modelling of the phenomena under study allows for the understanding of structural characteristics of the competition arena, as well as of how the interactions among first mover and follower generate the dynamics of the competition. With this first analysis, it is our goal to demonstrate the descriptive capability owned by the systems thinking approach in improving a company's understanding of the competition dynamics and hence its decision-making effectiveness when it comes to a new product launch and its diffusion on the market.

The proposed qualitative model was devised with causal-loop diagram (CLD) that consists of variables connected by arrows denoting the causal influences among the variables. In that we have included elements that have not been addressed by other previous works on this topic and we will argue that their inclusion in a systemic perspective might lead to future developments (in terms of quantitative transposition of the proposed model) that, matched with a few well-known case-studies, could bring to the identification of effective policies in using different marketing tools according to a phased-approach timing. 
In particular, it will be interesting to have the possibility to conduct some scenario analysis using a good system dynamics simulation model based on this CLD (which is the natural and quantitative development of systems thinking).

In this way, we will try to figure out whether this qualitative structure is actually capable in constituting a tool to support decisions for strategic management.

If we are right, managers could assess their strategies in a synthetic simulation environment before implementing them in the real world, thus preventing any risks of those tactics later proving to be eventually wrong.

\section{Literature review}

The phenomenon of the diffusion of a technology or product has already been studied in the past by experts and researchers who have tried to define it by means of various models. Rogers (1962), for instance, identified the main items involved in the diffusion phenomenon and divided them into categories; on another account, Bass (1969) analytically tried to create a mathematical function that is as close as possible to the reality, by referring to data deductible from the context. In the following, we will report on a few of these theories.

\subsection{Rogers model}

The Rogers (1962) diffusion model describes and explains the process by which innovations are diffused and adopted in the consumer community. The model identifies which people adopt first and which later (the adopters' category).

The performance of the S-shaped diffusion curves of this model can be interpreted according to the different time of adoption of the product from potential customers who differ by risk attitude, by degree of involvement and by economic availability. In fact, the diffusion model suggests that, over time, the diffusion process is described by a frequency curve shaped as a bell. The consumers, based on the moment of their entry in such frequency curve, are divided into five categories: innovators, early adopters, early majority, late majority and latecomers. Rogers also noted that influence from people is much more significant than that of the mass media. The latter, in fact, have the power to inform, but is much weaker in persuasion compared with the personal communications. Last but not least, the Everett model does not include a timing function that describes how adopters change in time, nor any marketing effect.

\subsection{Bass model}

The theoretical assumptions from which Bass (1969) has written his article is based on the division of the buyers in two categories: innovators and imitators.

The behavioural theory asserts that innovation (that is the product) is first adopted by a small group of innovators who, afterwards, affect (by word of mouth communication) the behaviour of other consumers. It means that innovators are influenced in their buying behaviour only from the official news (mass-media), while the imitators are influenced mainly by information by word of mouth. 
The Bass model has been successfully applied in the explanation of diffusion processes for a large number of innovations: durable consumer products, industrial processes medical equipment and telecommunications systems.

However, there are many limits to this model. The model assumes the occurrence of a complete communication between all members of the social system. It also assumes that somehow there is a global or comprehensive interaction between all the 'actors' involved in the phenomenon. A major limitation of the Bass model is the fact that such modelling does not take into account the influence exerted by the marketing mix variables on the diffusion process, variables under direct control of managers such as pricing or advertising strategy. Furthermore, diffusion parameters do not change over time, innovation and imitation coefficients are always the same (Chandrasekaran and Tellis, 2007).

\subsection{Generalised Bass model}

Bass et al. (1994) propose a general form of the Bass' equation that incorporates the effects of marketing-mix variables (Kotler and Armstrong, 2009) on the likelihood of adoption. This means that decision variables can shift the Bass curve in time, but in the result the shape of the curve is always similar. In fact, the function acts on the diffusion modifying its temporal structure, but does not change the values of its internal parameters; the significant effect of $\mathrm{x}(\mathrm{t})$ is to advance or delay the adoptions, but not to increase or decrease them; it means that the function represents all the strategies applied to control the timing of a diffusion process, but not its size.

The major limitation of this extended Bass model is that it does not consider effects due to possible competitors, the presence or absence of a competitor change deeply the diffusion dynamic and the brand's decisions about marketing.

Although these past studies have been widely acknowledged and appreciated and represent a solid foundation for anyone wishing to tackle a study in this field, they have a lack of systemic perspective which might provide some useful insights about the complex system of a new product launch.

Recently, there were some studies which were based on the systems thinking/ system dynamics approach to support managerial actions for a firm's success. We have performed a literature research on the digital library system at the Sapienza University of Rome (equipped with the EBSCOhost Research Databases). We have used the following keywords combinations:

- $\quad$ system thinking and marketing strategy

- $\quad$ system thinking and word-of-mouth

- $\quad$ system thinking and new product diffusion

- system thinking and customer satisfaction.

During the selection process, non-relevant articles were identified and excluded. Among the rest we have chosen those which show a system thinking model. 
The first we present here is about new product diffusion, the second is about word-of-mouth phenomenon and the third organisational IT investment competition strategy.

\subsection{Hrvoje Kalinić, Zvonko Kostanjčar and Branko Jeren model}

This study proposes a model of product diffusion in the market based on the concepts of systems thinking and the methodology of system dynamics. The model focuses on comprehensiveness, and it helps the management to understand the diffusion process. The purpose of the model is to describe how the market will accept a product depending on its specific characteristics. Based on the predictions, it is possible to choose the optimal characteristics of a product for the predefined market (Kalinic et al., 2010).

This model is strictly related with Rogers' diffusion model and in which try to extend it including some other factors like advertising and personal influence effects; these two last factors are in line with Bass model.

As this model is a sort of combination of both Rogers and Bass models, there are not variables or factors that explain what are the effects due to a potential market competition or due to the customer experience and satisfaction.

\subsection{Roman Wong and Shirley Ye Sheng's model}

The objective of Wong and Sheng's (2012) study is to construct a computational architecture and use it as a simulation tool for the study of the dynamic recursive relationship between consumers' decision to adopt a product and to show how the adoption experience may trigger their contribution of word-of-mouth messages to online review websites, which frequently exert impacts on other potential adopters.

Using data about a certain model of digital camera on a leading shopping website, they demonstrate that their model has a gamma distribution pattern, as it happens for new product adoption.

This model is strictly focuses on word-of-mouth effect and its evolution in time, so there is no marketing tools implementation or competition effects (the switching phenomenon is simply mentioned).

\subsection{Yi-Wen Liao, Yu-Min Wang, Yi-Shun Wang, Yi-Min Tu model}

This study, based on a combination of the balanced scorecard method and a whole perspective of system dynamics, develops a simulation model of organisational IT investment strategy portfolios, and discuss the establishment of an effective investment strategy portfolio for long-term competitive advantage within a competitive marketplace environment (Liao et al., 2015).

This model aims to provide a decision support tool for IT manager giving a long-term and nonlinear perspective with system dynamics approach.

The model needs more empirical data to validate the relationships between the variables and the investigation is limited to two competing companies of the same scale and competitiveness. Furthermore, the model does not show variables that might describe firm's marketing effort. 
Figure 1 Hrvoje Kalinić, Zvonko Kostanjčar and Branko Jeren model

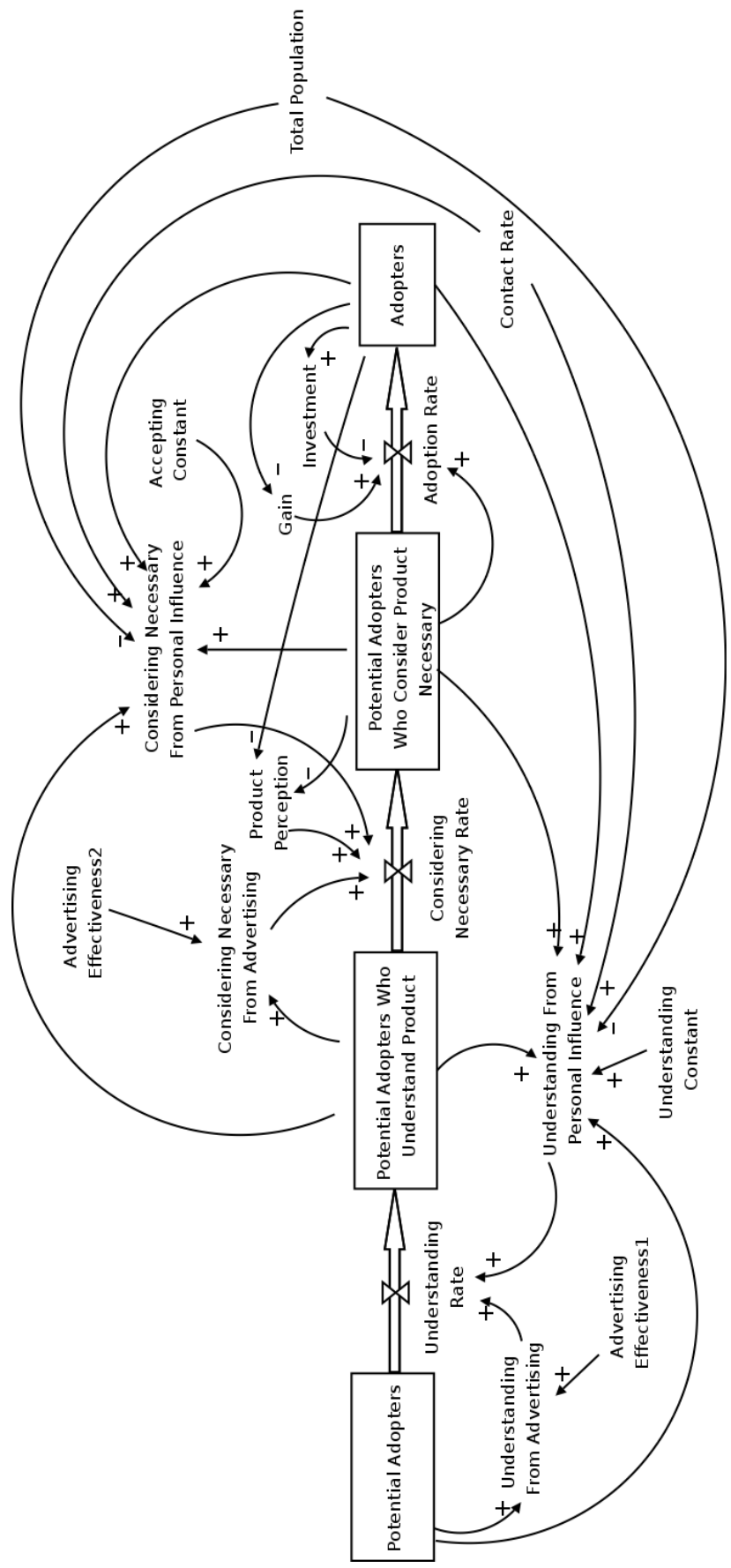


Figure 2 Wong and Sheng system-dynamics model (see online version for colours)

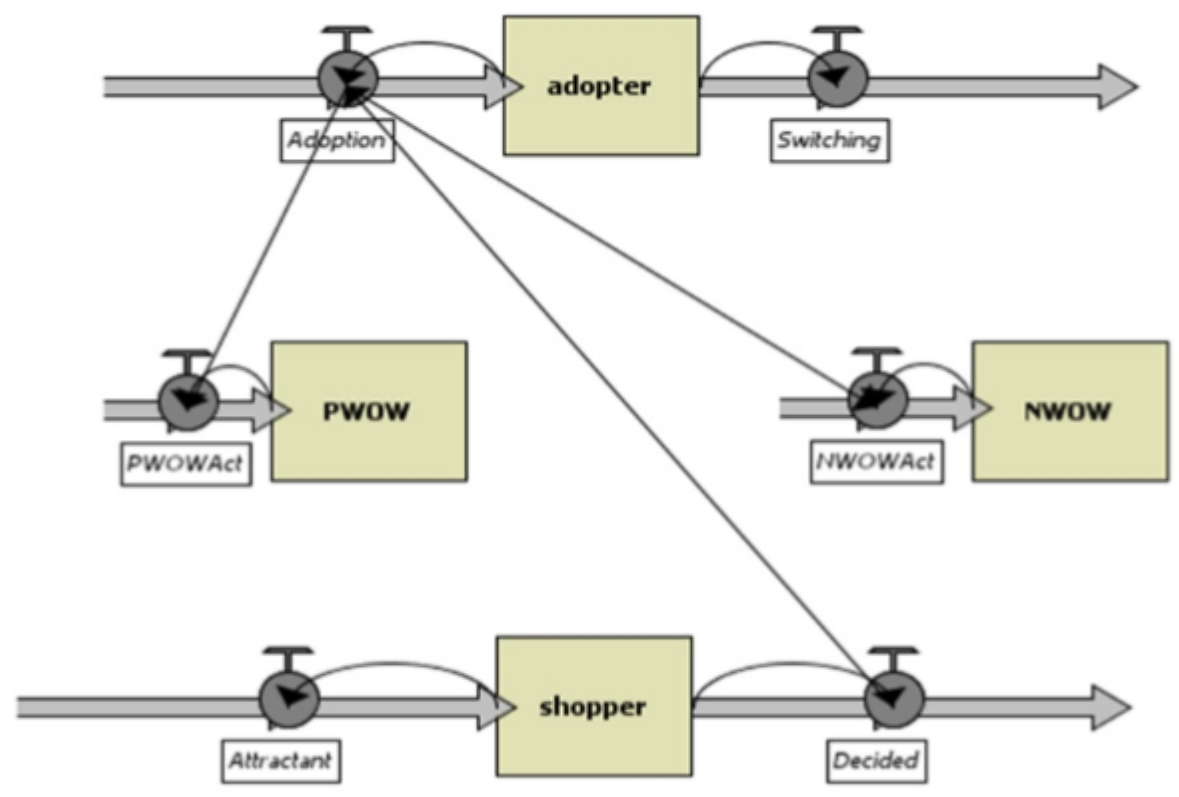

Figure 3 Liao et al. model (see online version for colours)

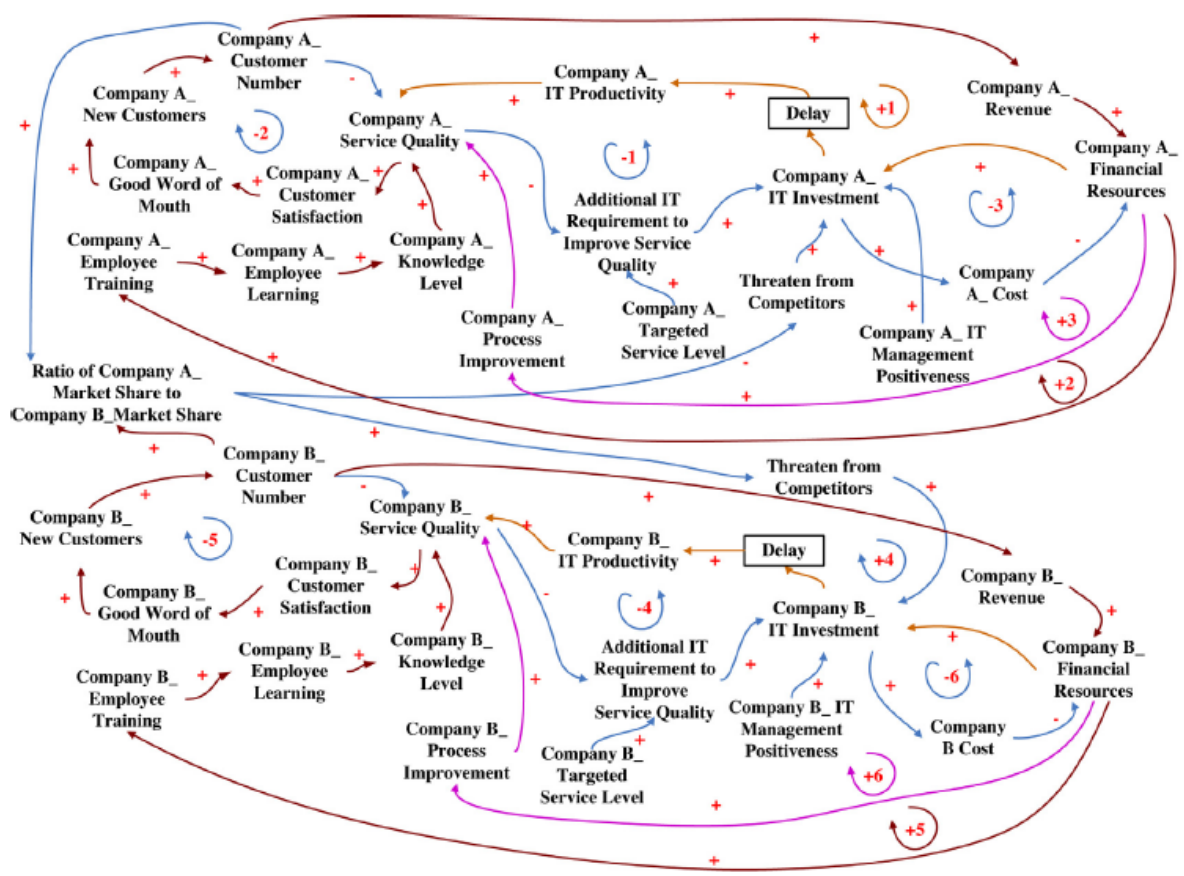


In Table 1, we analyse the key points of the above presented theories.

Table 1 Key points of past theory and models

\begin{tabular}{lcccccc}
\hline & $\begin{array}{c}\text { Customers } \\
\text { category }\end{array}$ & $\begin{array}{c}\text { Differential } \\
\text { equations }\end{array}$ & $\begin{array}{c}\text { Marketing } \\
\text { tools }\end{array}$ & $\begin{array}{c}\text { WOM } \\
\text { effect }\end{array}$ & $\begin{array}{c}\text { Competition } \\
\text { effects }\end{array}$ & $\begin{array}{c}\text { Customer } \\
\text { satisfaction }\end{array}$ \\
\hline Rogers & $\mathrm{X}$ & & & & & \\
Bass & & $\mathrm{X}$ & & $\mathrm{X}$ & & \\
Generalised Bass & & $\mathrm{X}$ & $\mathrm{X}$ & $\mathrm{X}$ & & \\
Kalinic et al. & $\mathrm{X}$ & $\mathrm{X}$ & $\mathrm{X}$ & $\mathrm{X}$ & & \\
Wong and Sheng & & $\mathrm{X}$ & & $\mathrm{X}$ & & \\
Liao et al. & & $\mathrm{X}$ & & $\mathrm{X}$ & $\mathrm{X}$ & $\mathrm{X}$ \\
\hline
\end{tabular}

\section{Systems thinking methodology}

System dynamics, proposed by Forrester (1961), is based on the concept of feedback control theory in system engineering. Through simulations system dynamics intends to investigate complex systems in the society; furthermore, it deals with the decision-making problem in business, industry, economy, etc. (Sterman, 2000). The features of system dynamics include nonlinearity, information feedback, time delay, and dynamic complexity (O'Connor and McDermott, 1997). Information that might be deduced from such methodology is based on the creation of a CLD, in which causal feedback loops can be identified. These loops are the result of a combination of causal links between variables. Links can be of two types:

- $\quad$ Positive (S): when the independent variable (arrow tail) changes, then the dependent variable (arrow head) changes in the same direction.

- Negative $(\mathrm{O})$ : when the independent variable (arrow tail) changes, then the dependent variable (arrow head) changes in the opposite direction.

There are two types of feedback loops: reinforcing feedback loop and balancing feedback loop [Figures 4(a) and 4(b)]. Also, it is possible to indicate a time delay between two variables [Figure 4(c)].

Figure 4 (a) Reinforcing loop (b) Balancing loop (c) Balancing loop with delay (see online version for colours)

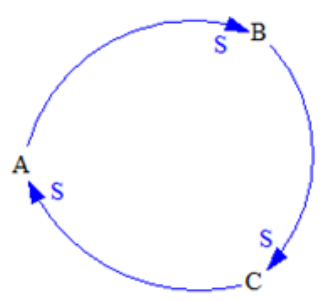

(a)

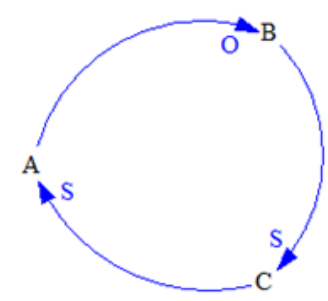

(b)

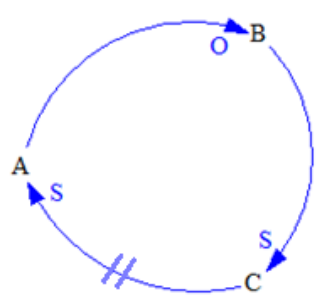

(c) 
Positive, negative, and delay loops form a system archetype, which can assist in taking a closer look at the problems and diagnosing the optimal solution (Mirchi et al., 2012).

Systematic archetypes are modular structures that highlight a particular behavioural pattern. They can be used, individually or together with others, to explain a set of behaviours that can be found in the evolving observable variables of a system.

The Fifth Discipline by Senge (1990) states that "If reinforcing and balancing feedback and delays are like the nouns and verbs of systems thinking, then the systems archetypes are analogous to basic sentences or simple stories that get retold again and again."

Therefore, founding these types of patterns inside a system, it is possible to give a deeper explanation about its dynamics and performance. Thanks to this, the following actions for fixing systemic problems will be more accurate and thorough.

For these reasons, CLD will be the tool being used for the analysis we will carry out through this paper, which is typical of the systems thinking approach. As said before, this approach allows studying complex problems, that are often constituted by a lot of variables, by building qualitative and quantitative models, through which mutual influences and interdependencies among a system's many variables are elicited: in this way we have the possibility to learn and gain fundamental insights on a system's structure and behaviour (by being able to see the feedback loops easier and analysing them effectively), hence improving our possibilities of controlling the problem under study.

\section{The systems thinking approach for the analysis of marketing competition}

As we reported in our literature review above, some past studies focused their attention on some aspects and not on other ones. For example, the model by Kalinic et al. considers both marketing and word-of-mouth effects but it does not give any indication in the case of competition with other firms, nor it includes any aspect related to customer care; conversely, the model by Liao et al. describes both competition effects and customer satisfaction, but does not address effects derived from marketing tools.

Since a systems thinking approach can deal with a large number of variables, we have tried to link all the relevant elements presented in Table 1 in one single model, at the same time by trying to not overload it and to keep its level of complexity at a very low level. Therefore, our model differs from the others because it addresses, one by one, the following factors, exploring and analysing their role within the phenomenon under study:

- customers category

- differential equations

- $\quad$ marketing tools

- WOM effect

- competition effects

- customer satisfaction. 
Our study starts from the assumptions of the Bass model, with the goal of developing a tool to provide strategically decision support system to a modern firm who wants to launch a product on the market: such a company will have to hardly cope with the public who, thanks to the communication tools available to everyone, is informed of almost everything and it can compare products very easily (Phau and Poon, 2000).

Also, it is very difficult today to be 'alone' for a long period in a newly born market, as there are a lot of firms, in every sector, competing for its leadership and there is almost no possibility to invest and start making profits without somebody noticing. So, it is important to keep in consideration the possibility of undergoing (sooner or later) competition, possibly by trying to delay a competitor's entry as much as possible.

In the initial phases, when a company enters the competition, the financial side is important too. In fact, today it costs more to bring a new product to market. Product innovation is becoming more targeted while supply chain complexity is rising (Cecere, 2013). Hence, it is essential to understand which aspects must be developed, not only because an action can be more effective than another, but also because that action can be more economic in relation to the available funds.

Bass, in his model, argued about innovation and imitation coefficients that define the context in which the phenomenon grows, defining how people react to an innovation. Our study's scope is to understand by what these coefficients are influenced, so to be able to better and more efficiently act on them.

The coefficients will be influenced by the company through several modern marketing tools we chose two types which we consider the most influential currently:

- Social media marketing because social networking sites are bound to bring in more customers for the business and much more promotions and marketing thus making social media, the better platform for marketing (Saravanakumar and SuganthaLakshmi, 2012).

- Public relations because there is a growing organisational acceptance of public relations as a necessary and effective strategic management function (Waddington, 2015).

With the help of a future quantitative model we might show that there will be different effects and different changes during the product diffusion depending on the monetary effort on each of these tools, keeping an eye on finances and avoiding to extra-spend with comparison to one own financial availability.

The marketing department power, defined as the ability to influence other people and departments in the firm (Hickson et al., 1971), predicts firms' future financial performance (Feng et al., 2015), so the marketing process has become over time an important factor for firms but at the same time it proves to be increasingly complex to predict its own effects in the short and long terms. Some effects are easily observable in the short term, other effects (which often they are the more relevant) cannot be understood and cannot be related to their true causes as they are most of the times distant in time. The systems thinking approach is pretty well indicated for those complex systems that have outcomes difficult to understand (especially if we do not study their structure, composed of feedback loops and systemic interrelationships).

Starting from these assumptions, we started our qualitative modelling phase by using CLDs, as one of the main tools of the systems thinking approach (Sterman, 2000). During the description of the developed CLDs, we will argument on each feedback loop that has 
been identified. The initial assumptions for our model are that the product is accepted by market and that it has a long-lasting success; also, for simplicity, we assume that only two firms are sharing most of the market for that specific product. The latter hypothesis does not affect the model too much, because even considering the presence of multiple firms at the first stage of this new born market, generally in the long term only two of those will survive and they will be recognised as the most favourite choices among consumers (Ries and Trout, 1997). This choice has been taken because, considering more firms, the model might become too much complex.

For a better visual understanding, in this overall map positive casual links were coloured blue and negative causal links were coloured red.

Figure 5 Overall qualitative model (CLD) (see online version for colours)

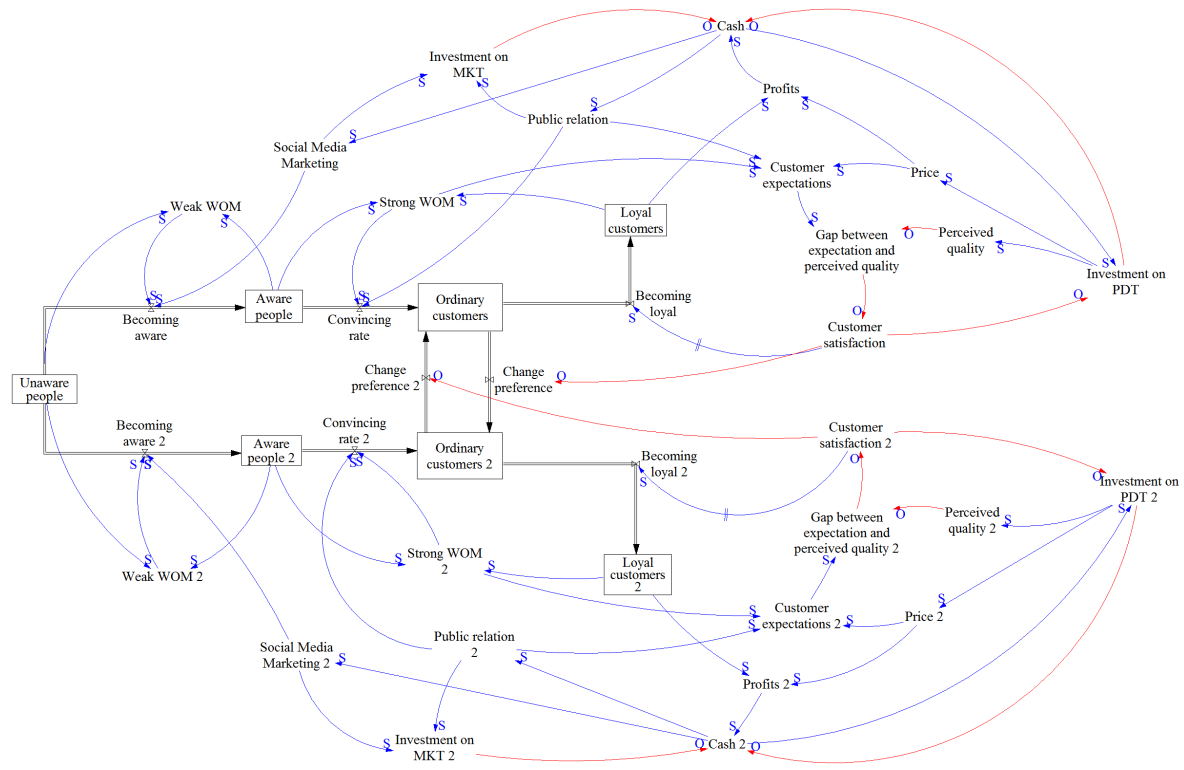

Below, only variables and feedback loops belonging to one of the two firms (first mover and follower) will be presented; the other ones, being symmetrical, will have the same characteristics.

The phenomena that we want to model start when a firm decides to launch a new product on the market assigning to this product its own brand. At first, it will be the only one on the market but soon, if the product starts to be well accepted by the market, some 'followers' appear, among which one will be recognised as a convincing alternative to the first mover (Ries and Trout, 1994). The dynamic situation we want to describe with our model is exactly placed in this time interval: consumers know the new product and its features, but they do not know which brands commercialise it yet, nor which brand is the best (so they do not know from whom to buy yet).

In this scenario, the two brands will try to make themselves known by consumers by using all sort of means, especially social media marketing, because internet advertising is an important marketing tool in boosting brand awareness (Chan et al., 2015), so thanks to this channel a large part of consumers will find out which brand sells the product they are 
interested in; this is important not only because in the future they might look for additional information about such brands, and accordingly they might decide to test a new product or another, but also because they might communicate the marketing message also to all their acquaintances and relatives, thus making the diffusion of information much faster (Mangold et al., 1999; Trusov et al., 2009). This type of peer-to-peer information sharing is called word-of-mouth, in this specific case we decided to call it 'weak WOM', because this type of WOM transmits only the simple message that a brand, which offers that kind of product, exists. Since who is transmitting the message has not yet tried the product, there is not an effective influence that might push consumer to try the product for the first time.

Figure 6 Weak WOM feedback loops (see online version for colours)

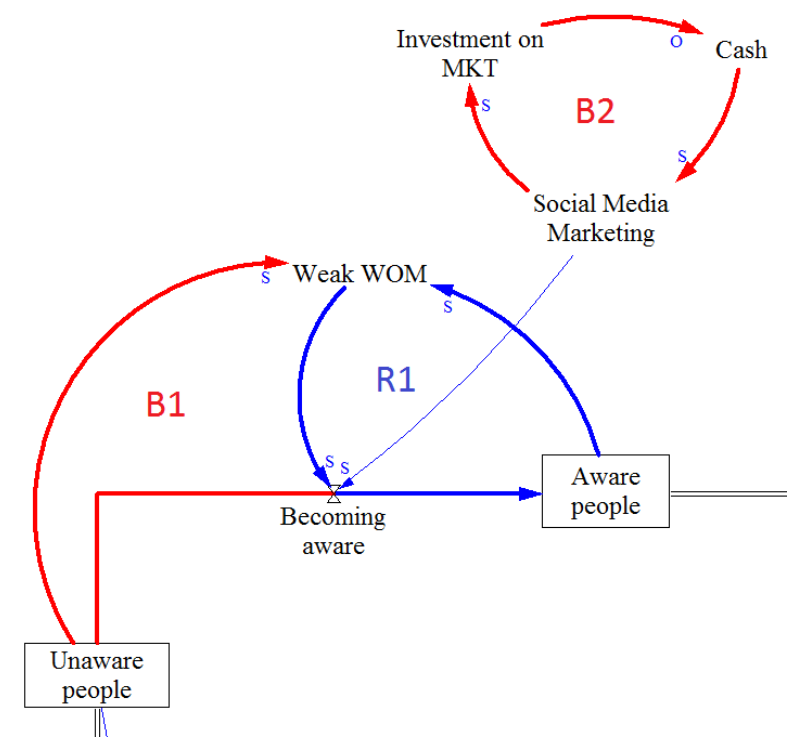

During this phase, we can see how the first feedback loops take shape.

- The blue-coded feedback loop labelled as R1 shows how, by increasing the number of aware people through social media marketing, the effect of weak WOM becomes more and more consistent and therefore increases the rate becoming aware.

- $\quad$ The red-coded feedback loop labelled as B1 shows the saturation phenomenon of unaware people that in the long run will tend to soften Becoming aware rate until all the people become aware.

- The red-coded feedback loop labelled as B2 shows the resource constraint (cash) that will limit efforts in social media marketing.

In addition to making the brand known to potential customers, a firm should convince them about the quality of their brand and about the fact that its product can actually meet their needs. In fact, a single consumer will buy the product only when he recognises its quality and its capability to respond to his needs (Stavkova, 2008). 
According to our studies, there are two important mechanisms that push consumers to try for the first time a new product: WOM and public relations.

Public relations comprises a range of activities conducted by organisational agents (employees or temporary consultants) that are designed to contribute to the effectiveness of the organisations they represent by improving organisational relationships with stakeholders and the media (L'Etang, 2012).

$W O M$, as said before, is a peer-to-peer exchange of information between persons who, in this case, talk about a certain product or service. In this point of choice pipeline, consumer will buy the product if he is convinced of his choice, one of the reasons why this happens is that he receives a positive WOM from who have already tried product, we call this different type of WOM as 'Strong WOM', i.e. a WOM that not only informs, but also convinces to buy.

Strong WOM is pushed mainly by a particular typology of customers, i.e., loyal customers (Gould, 1995). Loyal customers are customers that have had an excellent experience and they are tied to a certain brand in a strong way (Gremler and Brown, 1999).

Figure 7 Strong WOM feedback loops (see online version for colours)

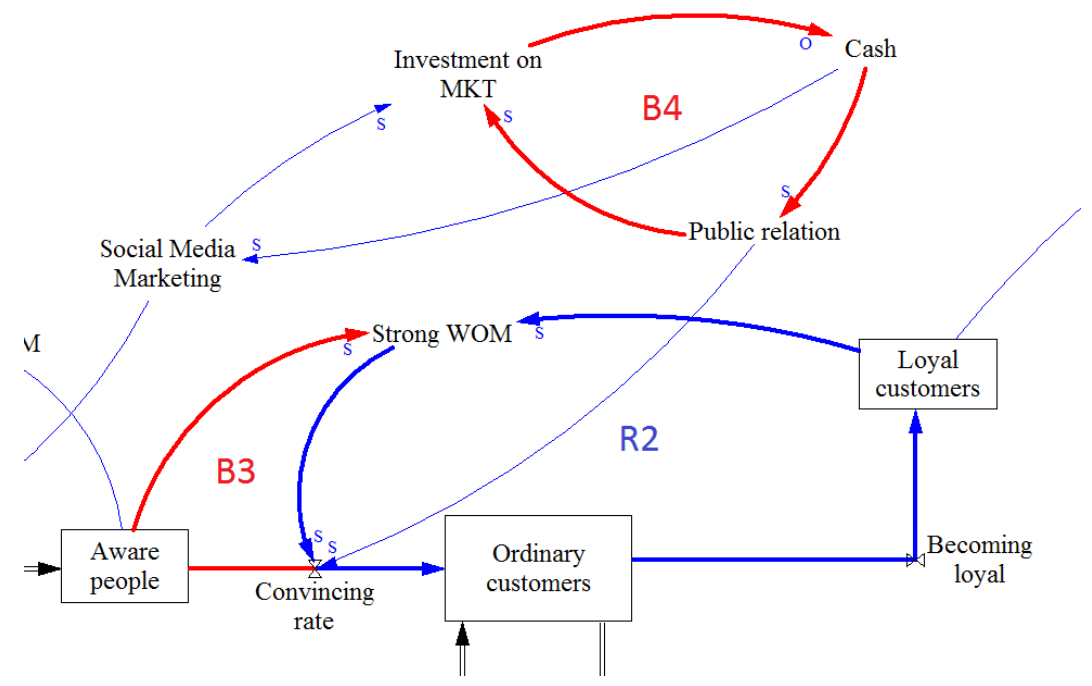

Other feedback loops generate the dynamics which are characteristics of this second phase:

- The blue-coded feedback loop labelled as R2 shows the reinforcing relation between loyal customers, ordinary customers and strong WOM.

- The red-coded feedback loop labelled as B3 shows the saturation phenomenon of aware people that in the long run will tend to soften convincing rate until all the people become customers.

- $\quad$ The red-coded feedback loop labelled as B4 shows the resource constraint (cash) that will limit efforts in public relations. 
Figure 8 Customer satisfaction feedback loops pt.1 (see online version for colours)

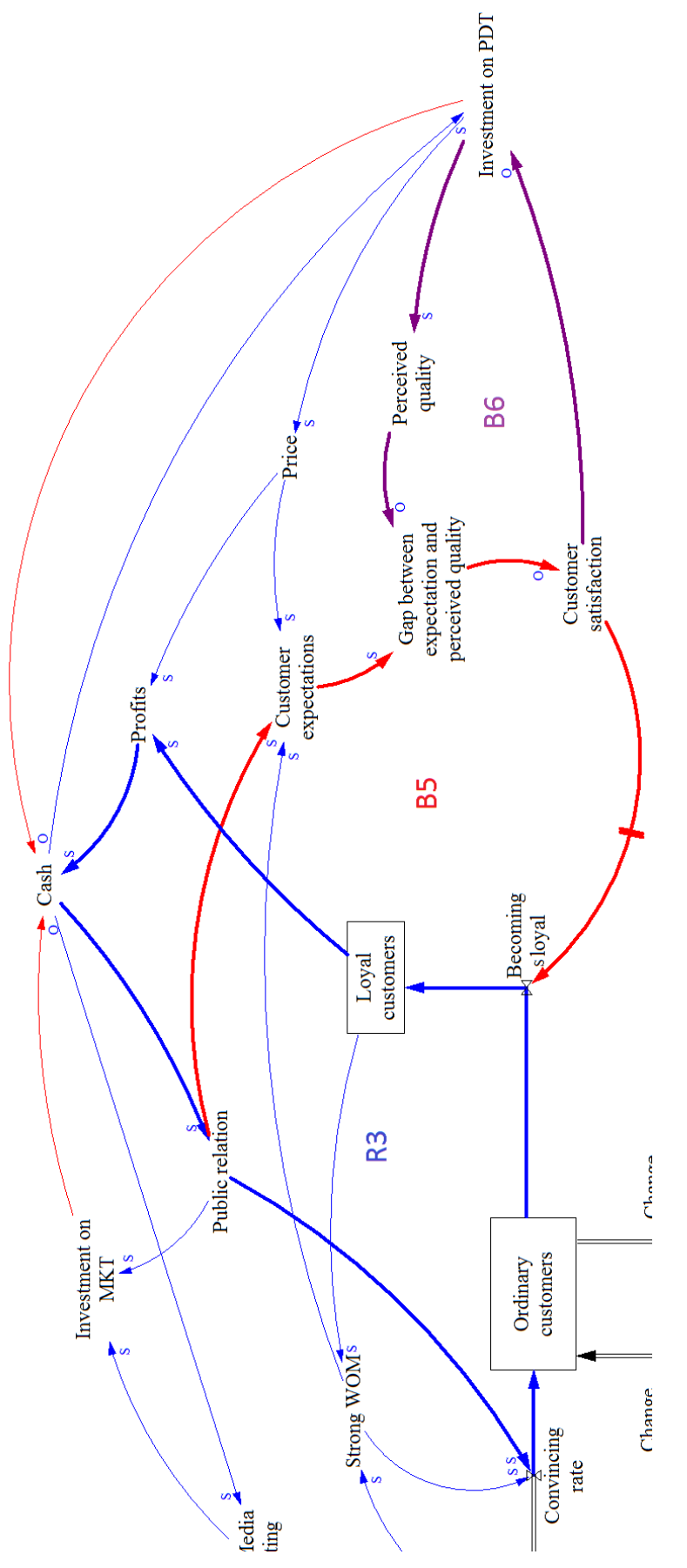


Figure 9 Customer satisfaction feedback loops pt.2 (see online version for colours)

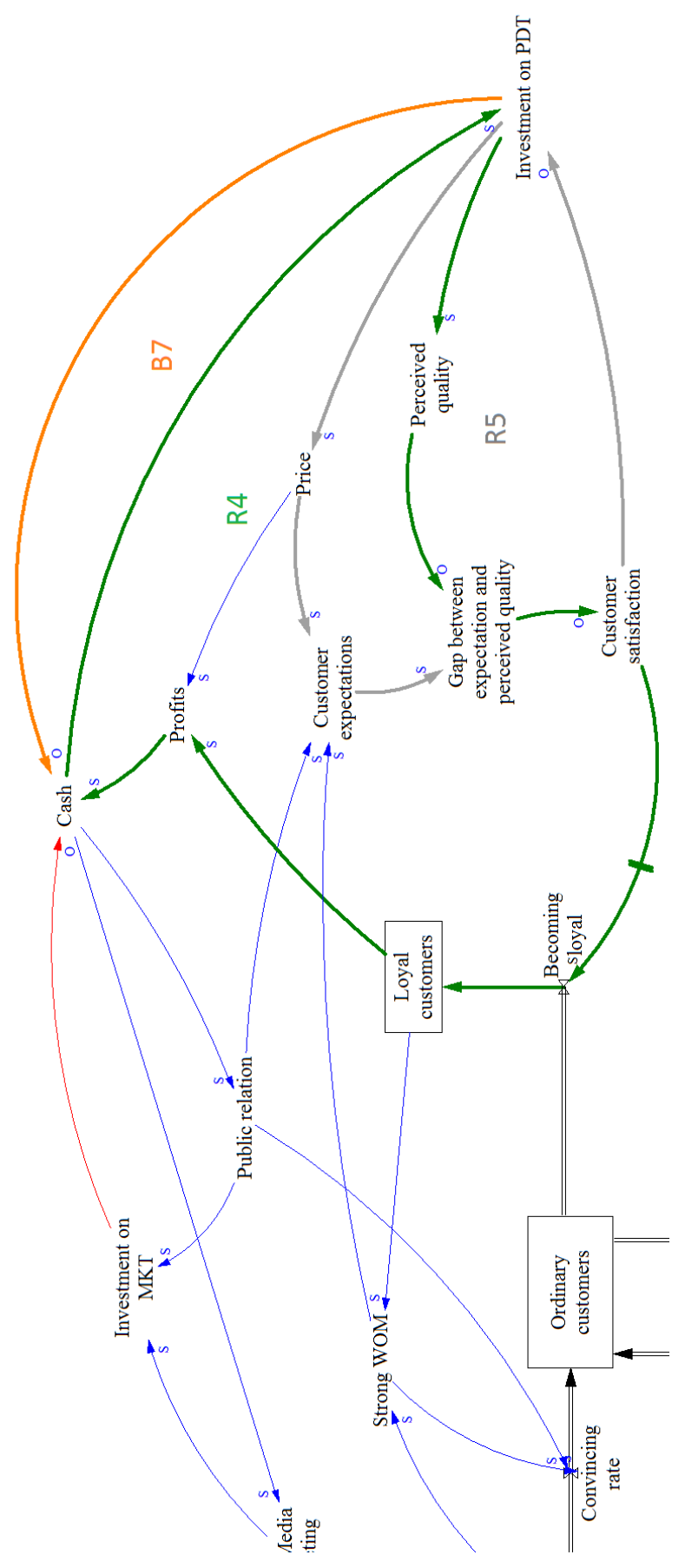


Marketers strive to initiate and maintain a long-term relationship between their brands and current and future consumers. In fact, some researchers view customer loyalty as a driver of customer lifetime value (CLV) because it can bring more future purchases and longer relationship duration (Qi et al., 2012; Bourdeau, 2005; Gwinner et al., 1998; Pritchard et al., 1992; Srinivasan et al., 2002). Moreover, as mentioned above, loyal customers represent a very important resource for strong WOM development.

As customer satisfaction has positive effect on customer loyalty (Gould, 1995; Sawlani and Jain, 2015; Lam et al., 2004), firm should try to satisfy its own customers through the product improvement and the product's service received. Customers need time to build trust and familiarity that causes a time delay in the relationship (Oliver, 1999; Delgado-Ballester and Munuera-Aleman, 2001). Customer satisfaction is given by a gap between what customer expects from a product and the quality that he actually perceived when he buys it (Hannan et al., 2016; Anderson, 1973).

Customer expectations for a product depend on certain factors, in particular: the higher the level of explicit quality promises, including advertising and other form of communication like public relation, the higher the level of expected quality; implicit quality promises, like price, elevate the level of expected quality; positive WOM elevates the level of expected quality (Zeithaml et al., 1993).

Customer satisfaction influences investments for product development because low satisfaction leads to claim increasing; accordingly firm reacts increasing quality of both product and related service (Chiou and Droge, 2006).

In turn, investments on product development and enhancing will influence price strategy, since firm will try to repay economic efforts made by raising the price.

The main feedback loops in this third phase are:

- The blue-coded feedback loop labelled as R3 shows how investments in public relations are important to create a good base of both loyal and ordinary customers, which will generate gains that can be reinvested.

- The red-coded feedback loop labelled as B5 shows how continuous investments in public relation lead to a rise in customer expectations, resulting in a fall in satisfaction and in becoming loyal rate too, all this creates a fall in profits and investment resources (cash).

- The violet-coded feedback loop labelled as B6 shows how investments on product will be balanced, because if firm improves overall quality, customer perceived quality will be improved in turn, so customers will be more satisfied, this positive outcome will mitigate investment.

- The green-coded feedback loop labelled as R4 shows how the process of continuous improvement of the product, if well conducted, leads to better economic results and therefore to investment capability.

- The grey-coded feedback loop labelled as R5 shows how investments on product, and the subsequent rise in price, lead to higher customer expectations, so in some cases the satisfaction will no longer be the same and this will generate the need for firm to make additional investment.

- The red-coded feedback loop labelled as B7 shows how investments on product are obviously limited by the amount of company's resources. 
Hypothesis we have assumed provide a competitor practically symmetrical to the first firm. As the market that we are studying is free market, ordinary customers, who have not yet decided to which brand they should finally trust, will go from one brand to another based on the experiences they have had with one or the other (Tsao et al., 2009). This phenomenon creates two flows of people: who goes from firm 1 to firm 2 and who does the opposite.

Change of preference for a specific brand happens when a customer no longer trusts in brand due to bad experience; this causes a fall in customer satisfaction, which increases his changing will (Baser et al., 2015).

Figure 10 Feedback loop relative to both firms (see online version for colours)

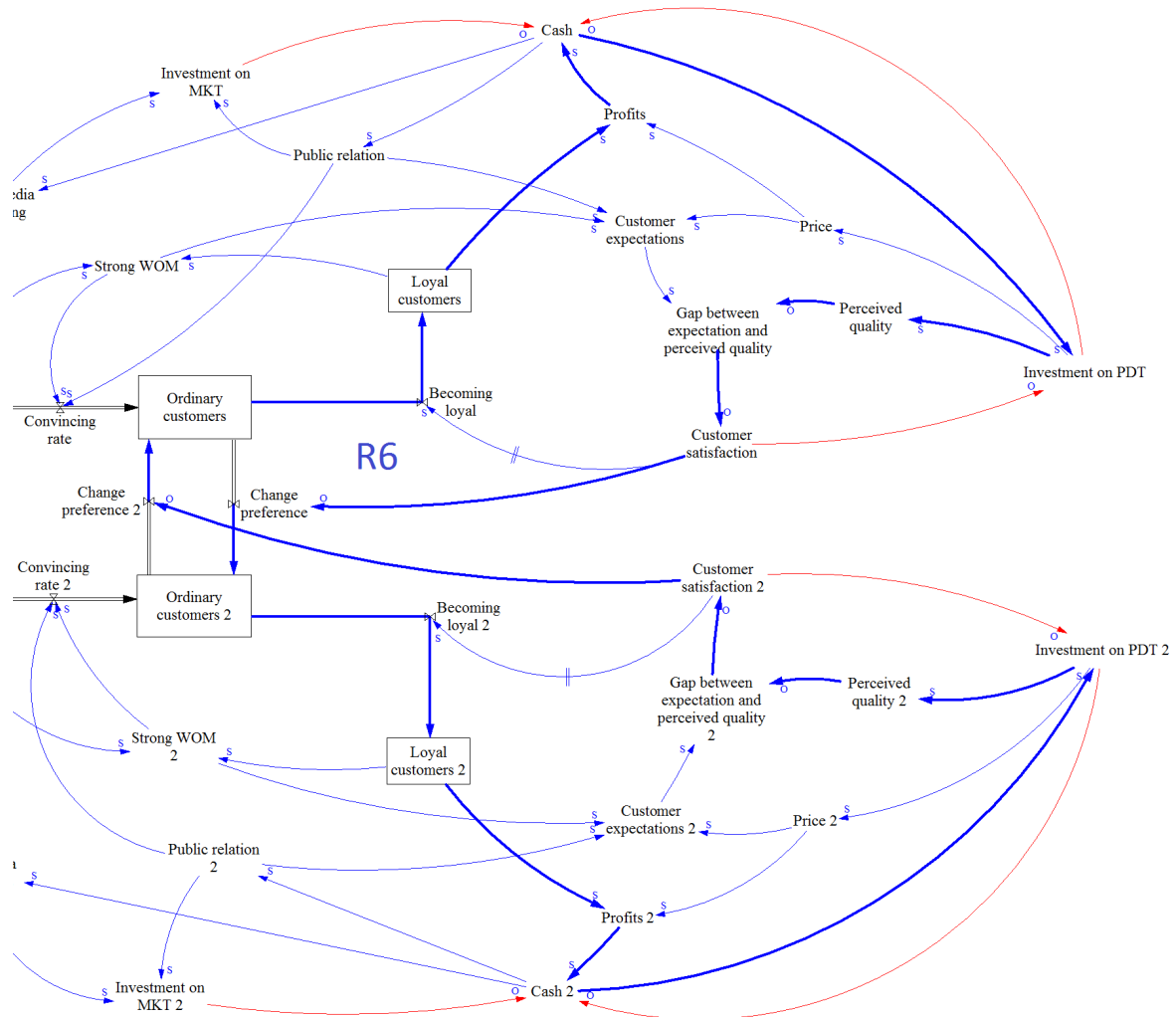

Main feedback loop in this final phase is:

- R6 is a self-reinforcing loop that links the two brands and shows how a loss of customers for a firm creates an advantageous situation for the other, who will have more resources due to achievement of unsatisfied customers, so it can invest, improve satisfaction of its own customers and decrease its switching phenomenon. This will give a disadvantage to those who suffer from loss of customers because it will have fewer resources to invest in its own customer satisfaction and therefore it will suffer more and more customer losses. 


\section{Findings and discussion}

By analysing the feedback loops in the presented CLDs, it is possible to get some important insights that might help firms on decision making and warn them about any side effects.

An example of this concept can be found by talking about public relations. If firm decide to invest on public relations in a strong way, it will increase convincing rate, so aware people will be convinced to buy for first time the product of that brand, overall result will be an increase of ordinary customers, with benefits from sales. In the other hand, improved public relations will increase customer expectations and accordingly the gap between expected and perceived quality, this effect will slow down becoming loyal rate, producing damage for firm because loyal customers represent the most important source of income. So it becomes quite clear that a strategy aiming at improving public relations should be accompanied with a congruous enhancement of product quality, in order to maintain the balance between what firm advertise in its marketing campaign and what type of quality its product can actually offer to consumers.

Another important aspect is related to investment on product and its feedback loops:

- If we consider the loops B6 (Figure 8) and R5 (Figure 9), we see that these loops balance each other, maintaining a certain level of gap between customer expectation and perceived quality. However, there is another loop that affects this subsystem, B5 (Figure 8), which starts when the price has not been set in the right way following a new investment on product. In fact, if the price is overrated compared to the effective rise of product quality, there will be a disequilibrium that will decrease customer satisfaction. This reduction produces two feedbacks: one returns to investments, raising them in order to regain the loss of satisfaction; the other passes through the rate 'becoming loyal', with a certain delay, and then it decreases customer expectation. This effect, happened with some delay, creates an unexpected variation of the gap between expectation and perceived quality which, in turns, causes a new variation of investment on product. This overall loop leads to an oscillation of product investment that is clearly harmful for the firm. The solution might be a very gradual product improvement action, avoiding heavy investments which might produce bigger oscillations on results, but above all, it is necessary to conduct a careful analysis on price setting, which must be as consistent as possible with quality perceived by customers.

\section{Conclusions and future developments}

The use of the systems thinking approach certainly becomes helpful to define an effective and flexible marketing strategy: it allows anticipating effects which otherwise are impossible to understand. Often, firms use the marketing leverage quite recklessly; using finances at their disposal in the wrong way and with the wrong timing, just too blindly 'perform sales'. This attitude can bring benefits in the short term (and not even always...), but shows its limits (and problems) when internal cycles, caused by actions made, appear completely.

A good way to avoid these problems is to use a serious strategy founded on systems thinking, not only to protect it from diffusion problems, but also to anticipate 
competitor's move and to be prepared to react in case of conflict. If a company acts in this way, it can develop a competitive advantage.

In this study, the phenomenon was preliminarily treated according to a qualitative approach, which represents a first step towards the future development of a quantitative SD model.

Condensing all aspects of the qualitative model into a quantitative one would constitute a huge step forward in our research, as it will allow the simulation of every scenario (in terms of market weight, investment and information) as well as to infer a huge quantity of data about consumers' moves and how they move from potential to effective costumers or from costumers of a brand to customers of another.

A future quantitative model will need a great amount of data, which unfortunately few firms currently have. Firms that have the competence can collect data from almost everything and, with the help of IT, they can extrapolate more information and they can use them to improve effectiveness on market. Generally, such data represent a competitive advantage, for this reason firms are reluctant to share this kind of data. However, firms could in turn reach a larger advantage by understanding in a better way their data and this can be possible with the tool that we have proposed in this study.

In this paper, we have assumed some hypothesis which allowed us building the proposed model. First of all, we assumed that product is successful and therefore it has a standard life-cycle as happens for widely used products, so this study will not give indications or advices for creating successful products, but it might be useful for helping firms during the phases of launch and diffusion of a product, facing diffusion problems and competitor's strategy in the correct way and with the necessary tools.

Furthermore, in this study, we have identified fundamental relationships in a market fight between two competing brands from a purely qualitative point of view, therefore future research might be conducted collecting data from past and present firms' results, in order to elaborate a quantitative model based on assumptions of the proposed qualitative model. Thanks to such data, not only the current model could be validated but also would be an opportunity to create an important tool to allow companies controlling their marketing strategies.

\section{References}

Adner, R. (2006) 'Match your innovation strategy to your innovation ecosystem', Harvard Business Review, Vol. 84, No. 4, p.98.

Anderson, R.E. (1973) 'Consumer dissatisfaction: the effect of disconfirmed expectancy on perceived product performance', Journal of Marketing Research (JMR), Vol. 10, No. 1, pp.38-44.

Baser, I.U., Cintamur, I.G. and Arslan, F.M. (2015) 'Examining the effect of brand experience on consumer satisfaction, brand trust and brand loyalty', Journal of Economic and Administrative Sciences, Vol. 37, No. 2, pp.101-28, Marmara University.

Bass, F.M. (1969) 'A new product growth for model consumer durables', Management Science, January, Vol. 15, No. 5, pp.215-227.

Bass, F.M., Trichy, V.K. and Dipak, C.J. (1994) 'Why the Bass model fits without decision variables', Marketing Science, Vol. 13, No. 3, pp.203-223.

Bourdeau, B. (2005) A New Examination of Service Loyalty: Identification of the Antecedents and Outcomes of an Attitudinal Loyalty Framework, $\mathrm{PhD}$ dissertation, The Florida State University, Tallahassee, USA. 
Cecere, L. (2013) New Products: More Costly and More Important, Forbes, 11 December [online] http://www.forbes.com/sites/loracecere/2013/12/11/new-products-more-costly-and-moreimportant/\#baeb6c86b901 (accessed 8 May 2017).

Chan, T.H., Leung, F.F., Tan, P. and Tse, D.K. (2015) 'Role of conventional ads in a digital age: effects of internet and conventional advertising on brand awareness and brand desire in China', International Journal of Electronic Commerce Studies, Vol. 6, No. 1, pp.87-98.

Chandrasekaran, D. and Tellis, G.J. (2007) 'A critical review of marketing research on diffusion of new products', in Malhorta, N.K. (Ed.): Review of Marketing Research, pp.39-80, M.E. Sharpe, Armonk, NY.

Chiou, J. and Droge, C. (2006) 'Service quality, trust, specific asset investment, and expertise: direct and indirect effects in a satisfaction-loyalty framework', Journal of the Academy of Marketing Science, Vol. 34, No. 4, pp.613-627.

Delgado-Ballester, E. and Munuera-Aleman, J.L. (2001) 'Brand trust in the context of consumer loyalty’, European Journal of Marketing, Vol. 35, Nos. 11-12, pp.1238-1258.

Feng, H., Morgan, N.A. and Rego, L.L. (2015) 'Marketing department power and firm performance', Journal of Marketing, Vol. 79, No. 5, pp.1-20.

Forrester, J.W. (1961) Industrial Dynamics, The M.I.T. Press, Cambridge.

Gould, G. (1995) 'Why it is customer loyalty that counts (and how to measure it)', Managing Service Quality: An International Journal, Vol. 5, No. 1, pp.15-19.

Gremler, D.D. and Brown, S.W. (1999) 'The loyalty ripple effect: appreciating the full value of customers', International Journal of Service Industry Management, Vol. 10, No. 3, pp.271-293.

Gwinner, K., Gremler, D. and Bitner, M. (1998) 'Relational benefits in service industries: the customer's perspective', Journal of the Academy of Marketing Science, Vol. 26, No. 2, pp.101-114.

Hannan, S., Suharjo, B., Nurmalina, R. and Kirbrandoko, K. (2016) 'The influence of perceived quality, perceived value, and customer expectation on customer satisfaction: an empirical study on independent surveyor industry in Indonesia', International Journal of Applied Business and Economic Research, Vol. 14, No. 2, pp.603-613.

Hickson, D.J., Hinings, C.R., Lee, C.A., Schneck, R.E. and Pennings, J.M. (1971) 'A strategic contingencies' theory of intraorganizational power', Administrative Science Quarterly, Vol. 16, No. 2, pp.216-229.

Kalinic, H., Kostanjcar, Z. and Jeren, B. (2010) 'A novel product development - key issues for success', Journal of Economic Computation and Economic Cybernetics Studies and Research, Vol. 44, No. 4, pp.179-198.

Kotler, P. and Armstrong, G. (2009) Principles of Marketing, 13th ed., Pearson, University of North Carolina.

Kuester, S., Homburg, C. and Robertson, T.S. (1999) 'Retaliatory behavior to new product entry', Journal of Marketing, Vol. 63, No. 4, pp.90-106.

L'Etang, J. (2012) Public Relations, The Wiley-Blackwell Encyclopedia of Globalization, Published Online, 29 February.

Lam, S.Y., Shankar, V., Erramilli, M.K. and Murthy, B. (2004) 'Customer value, satisfaction, loyalty, and switching costs: an illustration from a business-to-business service context', Journal of Marketing Science, Vol. 32, No 3, pp.293-311.

Liao, Y-W., Wang, Y-M., Wang, Y-S. and Tu, Y-M. (2015) 'Understanding the dynamics between organizational IT investment strategy and market performance: a system dynamics approach', Computers in Industry, Vol. 71, No. C, pp.46-57.

Mangold, G., Miller, F. and Brockway, G. (1999) 'Word-of-mouth communication in the service marketplace', Journal of Services Marketing, Vol. 13, No. 1, pp.73-89. 
Mirchi, A., Madani, K., Watkins, D. and Ahmad, S. (2012) 'Synthesis of system dynamics tools for holistic conceptualization of water resources problems', Water Resources Management, Vol. 26, No. 9, pp.2421-2442.

O'Connor, J. and McDermott, I. (1997) The Art of Systems Thinking, Thorsons, San Francisco, USA.

Oliver, R.L. (1999) 'Whence consumer loyalty?', Journal of Marketing, Vol. 63, No. 1, pp.33-44.

Penconek, M. and Sjöstrand, J. (2015) Nielsen's Breakthrough Innovation Report, Nielsen Company.

Phau, I., and Poon, S.M. (2000) 'Factors influencing the types of products and services purchased over the Internet', Internet Research, Vol. 10, No. 2, pp.102-113.

Pritchard, M.P., Howard, D.R. and Havitz, M.E. (1992) 'Loyalty measurement: a critical examination and theoretical extension, Leisure Science, Vol. 14, No. 2, pp.155-164.

Qi, J., Zhou, Y-P., Chen, W-J. and Qu Q-X. (2012) 'Are customer satisfaction and customer loyalty drivers of customer lifetime value in mobile data services: a comparative cross-country study', Information Technology and Management, Vol. 13, No. 4, pp.281-296.

Ries, A. (2005) Focus: The Future of Your Company Depends on It, Harper Business, New York, NY.

Ries, A. and Trout, J. (1994) The 22 Immutable Laws of Marketing: Violate Them at Your Own Risk, Harper Business, New York, NY.

Ries, A. and Trout, J. (1997) Marketing Warfare, McGraw-Hill Education, New York, NY.

Rogers, E.M. (1962) Diffusion and Innovations, The Free Press, New York.

Saravanakumar, M. and SuganthaLakshmi, T. (2012) 'Social media marketing', Life Science Journal, Vol. 9, No. 4, pp.4444-4451.

Sawlani, C. and Jain, R. (2015) 'A study on relationship between store loyalty and satisfaction in customers of organised retailers in indore', CLEAR International Journal of Research in Commerce \& Management, Vol. 6, No. 10, pp.26-30.

Senge, P. (1990) The Fifth Discipline, Doubleday/Currency, New York, NY.

Shilling, M.A. (2009) Strategic Management of Technological Innovation, 2nd ed., McGraw-Hill, New York, NY.

Srinivasan, S., Anderson, R. and Ponnavolu, K. (2002) 'Customer loyalty in e-commerce: an exploration of its antecedents and consequences', Journal of Retail, Vol. 78, No. 1, pp.41-50.

Stavkova, J. (2008) 'Factors influencing consumer behaviour', Agriculture Economics-Czech, Vol. 54, No. 6, pp.276-284.

Sterman, J.D. (2000) Business Dynamics: Systems Thinking and Modeling for a Complex World, Irwin/McGraw-Hill, New Yor, NY.

Trusov, M., Bucklin, R.E. and Pauwels, K. (2009) 'Effects of word-of-mouth versus traditional marketing: findings from an internet social networking site', Journal of Marketing, Vol. 73, No. 5, pp.90-102.

Tsao, H.Y., Lin, P.C., Pitt, L. and Campbell, C. (2009) 'The impact of loyalty and promotion effects on retention rate', Journal of the Operational Research Society, Vol. 60, No. 5, pp.646-651.

Waddington, S. (2015) Chartered Public Relations: Lessons from Expert Practitioners, Kogan Page, London, UK.

Wong, R. and Sheng, S.Y. (2012) 'A business application of the system dynamics approach: word-of-mouth and its effect in an online environment', Technology Innovation Management Review, Vol. 2, No. 6, pp.42-48.

Zeithaml, V.A., Berry, L.L. and Parasuraman, A. (1993) 'The nature and determinants of customer expectations of service', Journal of the academy of Marketing Science, Vol. 21, No. 1, pp.1-12. 